\title{
PEDAGOGITIS EN LA UNIVERSIDAD
}

\section{UNIVERSITY PEDAGOGITIS}

\section{AUTORES}

José Antonio Abad Baños: Profesor de la facultad de Química de la Universidad de Murcia (España).

jose.antonio@mixmail.com

\section{CURRÍCULUM VITAE}

Profesor de la facultad de Química de la Universidad de Murcia (España).

\section{RESUMEN}

En el I Congreso Internacional Docencia Universitaria e Innovación, recientemente celebrado en Barcelona, se ha presentado una serie de comunicaciones donde se pretende contribuir a la mejora de la docencia en la Universidad y donde se realizan afirmaciones como: La formación pedagógica del profesorado universitario es una de las cuestiones actualmente más debatidas en el seno de las mismas. Existen en la actualidad interesantes medidas formativas surgidas de los ICEs y otras instituciones.

\section{PALABRAS CLAVE}

Pedagogía - Universidad - Congresos - Innovación 


\begin{abstract}
In the First International Conference on University Teaching and Research, recently held in Barcelona, has presented a series of communications which aims to contribute to the improvement of teaching at the University and which are claimed as pedagogical training of university teachers is a currently the most debated issues within them. There are now interesting training measures arising from the ICEs and other institutions.
\end{abstract}

\title{
KEY WORDS
}

Education - University - Conference - Innovation

En el I Congreso Internacional Docencia Universitaria e Innovación, recientemente celebrado en Barcelona, se ha presentado una serie de comunicaciones donde se pretende contribuir a la mejora de la docencia en la Universidad y donde se realizan afirmaciones como: "La formación pedagógica del profesorado universitario es una de las cuestiones actualmente más debatidas en el seno de las mismas. Existen en la actualidad interesantes medidas formativas surgidas de los ICEs y otras instituciones". O como esta perla referida a la composición de las comisiones de contratación de plazas interinas y de tribunales de oposiciones, para optar a plazas de la universidad: "Para una mayor coherencia de la composición de los miembros del tribunal con los objetivos que se plantean en las pruebas convendría introducir la presencia de un algún técnico en pedagogía". No voy a comentar estas propuestas y otras surgidas en el citado congreso; personas mucho mejor informadas están 
tratando el tema (Ver el artículo de Guillem Bou, 2000: "La escuela invisible de la endogamia en la UAB", publicado en esta misma página, también disponible en http://www.geocities.com/guillembou/escuelaendogamia.html). Sin embargo, sí me voy a permitir hacer una serie de reflexiones relacionadas con la enseñanza universitaria.

En primer lugar hay que plantearse qué es un estudiante universitario: qué conocimientos, qué nivel cultural y qué técnicas de aprendizaje debe poseer para encarar unos estudios universitarios. Yo creo que debe ser una persona con un cierto nivel cultural y de conocimientos, capaz de entender, salvo aspectos técnicos que desconozca, una conferencia, de redactar un escrito acerca de lo que ha entendido de esa conferencia y que dicho escrito posea un nivel digno en cuanto a inteligibilidad, estilo y ortografía. Un alumno así, acostumbrado a enfrentarse a problemas intelectuales y a esforzarse en su comprensión podrá seguir las explicaciones de un profesor universitario que a su vez posea, en primerísimo lugar, un profundo conocimiento de la materia a impartir, lo cual se consigue mediante el estudio y el ejercicio profesional, léase investigación; en segundo lugar capacidad para ordenar y esquematizar adecuadamente la materia y en tercer lugar exponerla claramente pero suscitando en el alumno curiosidad y ganas de afrontar el desafío que implica entender y trabajar una ciencia.

Estas habilidades se consiguen con la experiencia y el apoyo de profesores más veteranos (antiguamente los maestros). ¿Qué pintan aquí los ICEs (Institutos de Ciencia de la Educación) y algunas de las conclusiones del congreso arriba comentado? Nada. De lo que se tendrían que preocupar es del lamentable estado intelectual de los jóvenes que acceden a la Universidad, fruto de los disparatados planes que se han ido perpetrando y que han culminado en la LOGSE. 
Desgraciadamente, el estudiante universitario que describo unas líneas más arriba era frecuente hace 30 años pero no ahora donde uno topa con analfabetos funcionales que jamás habrían superado la reválida de cuarto. Ahí es donde deben actuar los buenos pedagogos, en las enseñanzas primaria y secundaria con el fin de motivar y formar a los alumnos para no encontrarte en la Universidad algo así: "Oiga es que yo no me encuentro motivado". ¡Váyase usted a hacer puñetas y búsquese una carrera relacionada con viajar y con el sexo!

Hay que desterrar la incipiente "pedagogitis" promovida desde algunos ICEs que sólo conduciría a la "secundarización" de la Universidad, y no digo que haya que hacer desaparecer estos institutos. Tampoco pretendo decirles qué es lo que tienen que hacer, ellos sabrán, pero, entre otros cometidos, deberían vigilar el nivel de los estudiantes que acceden a la universidad y proponer soluciones que contribuyan a elevarlo. También, podrían decir algo de los libros de texto utilizados en primaria y secundaria; por citar un ejemplo, el libro de Lengua de mi hijo de once años es tan malo que parece que ha sido escrito por un analfabeto funcional.

Finalmente, otro punto de reflexion relacionado con el ser universitario se refiere a las carrerillas que vienen proliferando últimamente. Ésas en las que según el informe Bricall la investigación no es necesaria y cuyos profesores, por tanto, pueden pasar completamente de ella. Pues bien, tales estudios serán de formación profesional superior o como les quieran llamar pero nunca universitarios. Al final vamos a tener diplomaturas universitarias en peluquería o fontanería.

José Antonio Abad Baños es Profesor Titular de Química Inorgánica en la Universidad de Murcia

NOTA DE VIVAT ACADEMIA: Recomendamos a nuestros lectores, al hilo de lo tan brillantemente expuesto por nuestro compañero José Antonio Abad, que se den un 
paseo por la WEB de la UAH y se encontrarán una diplomatura en Turismo, lo cual no sería del todo grave, y unos ¡Estudios Propios en Hostelería! 